\title{
EVALUASI PENGIRIMAN VIDEO MENGGUNAKAN PENGKODEAN SKALABILITAS SPASIAL DENGAN GANGGUAN PADA KANAL INTERNET
}

\author{
Agus Purwadi ${ }^{1}$, Baharuddin ${ }^{2}$ \\ ${ }^{1}$ Jurusan Teknologi Informasi Politeknik Negeri Jember \\ 2 Jurusan Teknik Elektro Fakultas Teknik Universitas Andalas \\ ${ }^{1}$ agus_purwadi@polije.ac.id, ${ }^{2}$ baharuddin.abbas@ft.unand.ac.id
}

\begin{abstract}
Video transmission over the internet can be a great possibility of the existence of lost packets (packet loss) and load variations in a large bandwidth. This is a source of network congestion can interfere with the rate of data communication. In this paper the proposed planning optimal error control in scalable video transmission to a video coding technique FGS (Fine Granularity Scalability), which is an improvement on the MPEG-4 video coding, which has outputs are scalable base layer and layer Enhanchement that have different sizes and rates, which the application will be adapted to the transmission network conditions, the ultimate goal is to minimize any distortion from the source to the destination. In the simulation yields a value Peak Signal to Noise Ratio (PSNR) on the base layer of 29, $683 \mathrm{~dB}$ and 78,917 dB enhancemenet layer and the base layer for the MSE of $69,998 d B$ and 0,000834417 dB enhancemenet layer, Means Square Error (MSE) as the performance of the network system performance on video quality for both the base layer and layer Enhanchement
\end{abstract}

Keywords: FGS (Fine Granularity Scalability), motion vectors, channels, PSNR, MSE

\section{Pendahuluan}

Aplikasi komunikasi video merupakan suatu hal yang tidak asing lagi dan sangat popular pada saat ini, misalnya: video on demand, videophone dan video conferencing. Berbagai usaha untuk mendesain dan menerapkan pelayanan QOS (Quality of Service) banyak dilakukan, dimana dalam internet banyak didapati paket-paket yang hilang (packet loss) dan variasi pada beban yang besar dan ini merupakan kasus network congestion. Sebagian besar dari transmisi video dalam internet terdapat 2 komponen dasar yang digunakan untuk meningkatkan kinerja yaitu: congestion control dan error control. Pada congestion control dimasukkan rate control, rate adaptive encoding dan rate shaping. Untuk error control dimasukkan error resilience, FEC (forward error control), retransmission (feedback) dan error concealment.

Laju bit (bit rate) dalam suatu jaringan telekomunikasi akan selalu berubah atau bahkan bertambah dan berkurang seiring dengan kapasitas memori dari data yang ditransmisikan pada gambar 1, hal ini perlu dilakukan adanya kontrol laju bit (rate control) untuk menyesuaikan data yang ditansmisikan dengan kondisi jaringan. Kualitas gambar pada video sangat tergantung pada tersedianya bandwith dan tanpa adanya error pada data yang ditransmisikan. Suatu video sebelum ditransmisikan pasti melalui proses pengkodean (coding) dan kompresi dari data video itu sendiri. Pada pengkodean video akan menghasilkan aliran bit (bit stream) dari video yang dikodekan yang nantinya akan menghasilkan laju bit (bit rate). Sedangkan pada kompresi video yang fungsinya adalah untuk memampatkan data video dari yang memori besar, misalnya : format AVI (audio video interleave) menjadi video dengan memori yang lebih kecil, misalnya SIF (Source Image Format), CIF (Common Intermediate Format), atau QCIF (Quadrature Common Intermediate Format).

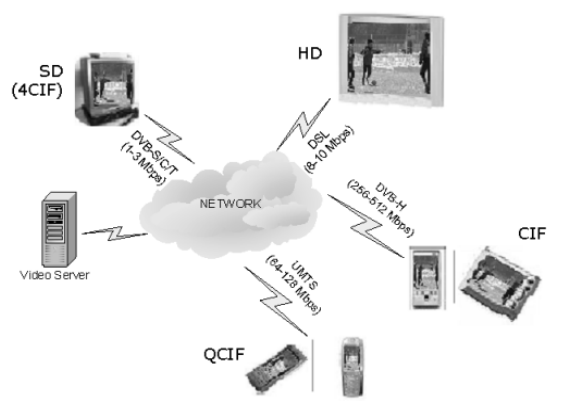

Gambar 1. Variasi terminal dan jaringan transmisi video 


\section{Permasalahan}

Untuk memecahkan masalah yang diakibatkan paket-paket yang hilang (loss) pada kanal dan untuk meningkatkan pelayanan QOS (Quality of Service), maka dalam penelitian ini direncanakan memfokuskan pada teknik skalabilitas pada output pengkodean video (video coding). Karena dengan teknik pengkodean spasial skalabilitas akan didapatkan output video dengan skala yang bervariasi dan tingkat laju bit (bit rate) yang bervariasi juga seperti ditunjukkan pada gambar 2. Hal ini difungsikan untuk menyesuaikan data video yang ditransmisikan dengan kondisi jaringan.
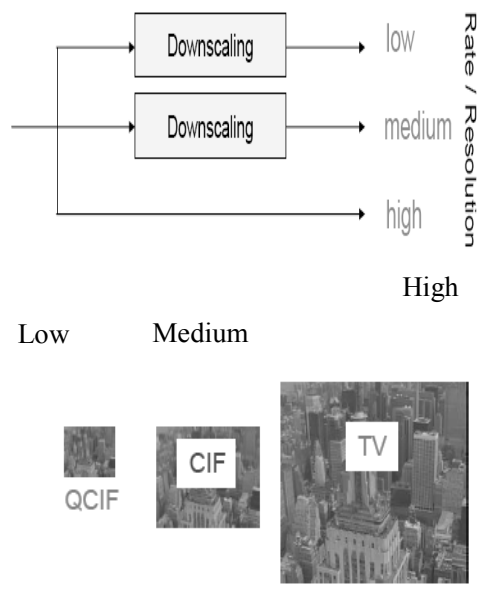

Gambar 2. Output Spasial Skalabilitas

Berdasarkan hal yang telah diuraikan diatas dapat dirumuskan masalahnya sebagai berikut:

a. Memperkenalkan suatu cara untuk mengkodekan suatu video dengan satu input yang menghasilkan beberapa output dengan format video QCIF, CIF atau HDTV yang diklasifikasikan dalam layer base dan enhancement.

b. Pengaturan pemodelan kanal yang akan digunakan sebagai media transmisi video dengan dengan model kanal unicast.

c. Pengaturan pengkodean kanal dari data bit video yang ditansmisikan menggunakan RS (reed Solomon).

d. Bagaimana memberikan evaluasi akhir berupa unjuk kerja kualitas video dalam berbagai macam performansi digunakan Peak-to-Peak Signal-to-Noise Ratio (PSNR) dan Mean Square Error (MSE) terhadap laju bit (bit rate) pada sistem kompresi video coding dengan skalabilitas layer base dan layer enhancement.

\section{Metode}

Sistem yang akan dilaksanakan pada penelitian ini adalah dapat dimodelkan seperti pada gambar 3 dibawah.

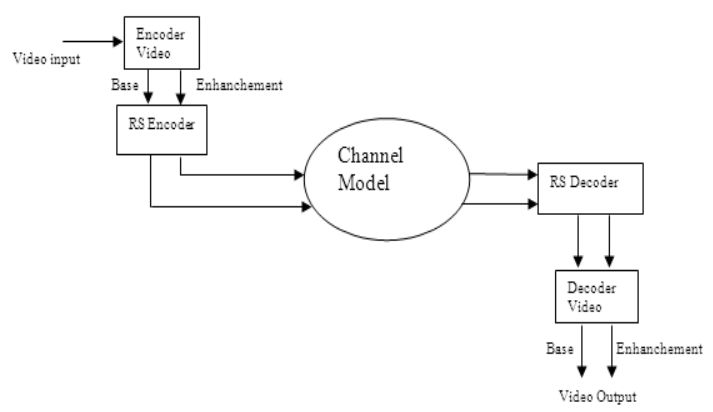

Gambar 3. Blok Diagram Pemodelan Sistem

Pengujian dilakukan terhadap PSNR dan MSE dengan bit rate-nya pada tiap-tiap urutan frame video. Selain itu, juga dilakukan penilaian kualitas frame video secara subyektif, yang berdasarkan hasil pengamatan visual terhadap urutan frame hasil rekonstruksi. Data video sequence asli yang digunakan adalah sequence Suzie dan Akiyo. Kedua video sequence ini mempunyai format QCIF (Quarter Common Intermediate Format) dengan ukuran pixel $176 \mathrm{x}$ 144, yang dalam mensimulasikannya dibagi dalam bentuk frame-frame untuk mengetahui unjuk kerja tiap-tiap frame dalam suatu sequence yang mana setiap frame merupakan citra grayscale dengan kedalaman bit sebesar 8 bit per piksel. Pengujian dilakukan dengan banyaknya jumlah frame dalam suatu sequence terhadap PSNR dan MSE.

\section{Penentuan Metode/Tools Untuk Mengolah Data}

Pada tahap selanjutnya adalah melakukan pengolahan data menggunakan program untuk dilakukan simulasi pada tiap-tiap blok sistem, yang dapat diuraikan sebagai berikut:

a. Encoder video coding menggunakan sistem FGS (Fine Granularity Scalability) pada MPEG-4, yang akan membagi video secara skalabilitas menjadi layer Base dan Layer Enhanchement.

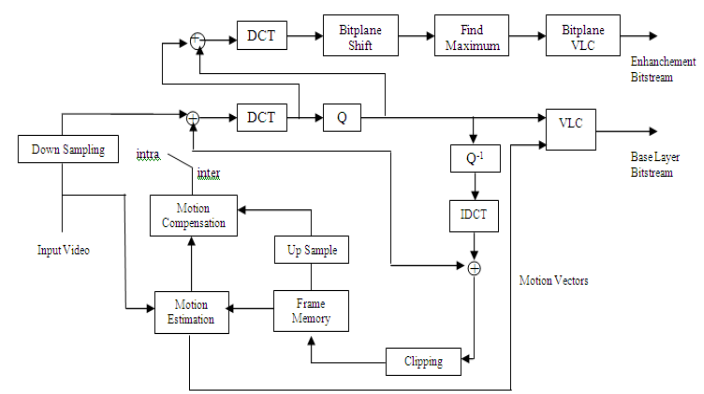

Gambar 4. Enkoder Pengkodean Video 
b. Encoder Reed Solomon merupakan pengkodean kanal yang akan merubah sinyal video menjadi deretan bit-bit yang akan ditransmisikan (bitstream).

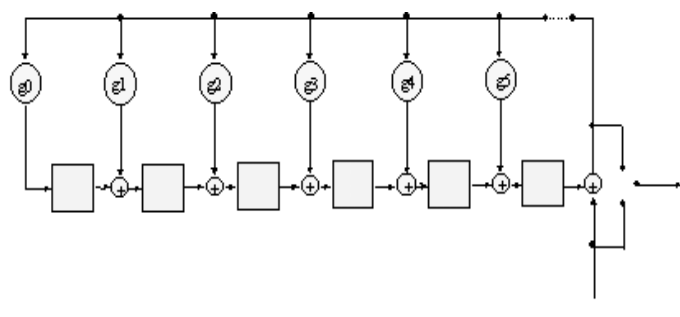

Gambar 5. Enkoder Reed Solomon RS $(255,249)$

c. Channel Model merupakan pemodelan kanal menggunakan model kanal unicast dengan transmisi error yang digunakan adalah dengan memberikan noise Gaussian (Additive White gaussian Noise) sesuai kondisi real. Pemberian Error (Lost vector) dengan noise Gaussian pada bidang spasial frame sequence Football dan Mobile dimulai pada frame ke-10 dengan kecepatan frame (frame rate) 30 frame/second, dengan parameter noise Gaussian :

$\mathrm{M}=16 ; \%$ Ukuran sinyal konstelasi

$\mathrm{k}=\log 2(\mathrm{M}) ; \%$ Jumlah bit per simbol

$\mathrm{n}=3 \mathrm{e} 4 ; \%$ Jumlah bit proses $=30,000$

nsamp $=1 ; \%$ Oversampling rate

$\mathrm{EbNo}=3 ; \%$ Dalam dB

d. Decoder Reed Solomon merupakan dekoding kanal yang akan mengembalikan bitstrem input menjadi sinyal video.

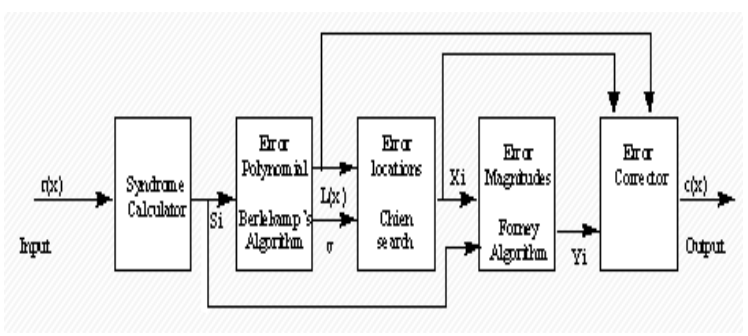

Gambar 6. Dekoder Reed Solomon

e. Decoder video coding menggunakan decoding video pada sistem FGS (Fine Granularity Scalability) pada MPEG-4, yang akan merekonstruksi sinyal video secara skalabilitas menjadi layer Base dan Layer Enhanchement seperti semula.

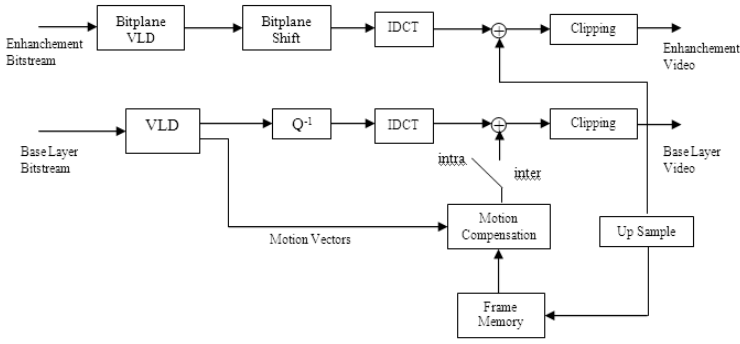

Gambar 7. Dekoder Pengkodean Video

f. Melakukan pengukuran pada input video pada sisi pengirim dan output video pada sisi penerima untuk kedua layer (base dan enhancement) dan dibandingan untuk mendapatkan unjuk kerja sistem yang akan menghasilkan parameter Mean Square Error (MSE) dan Peak Signal to Noise Ratio (PSNR).

\section{Hasil Simulasi}

Parameter simulasi yang dipergunakan untuk mendapatkan performansi dari unjuk kerja sistem dan untuk mendapatkan hasil pada proses video coding diperlihatkan pada tabel 1 dibawah.

Tabel 1. Parameter Simulasi

\begin{tabular}{|l|l|}
\hline Struktur GOP & IBBPBBP ...... \\
\hline Frame rate & $30 \mathrm{fps}$ \\
\hline Video Squence & Football \\
\hline Resolusi & $\begin{array}{l}352 \times \text { X 288 (CIF), } \\
\text { YUV 4:2:0 }\end{array}$ \\
\hline Jumlah Frame & 50 frame \\
\hline Channel Coding & RS (255,247) \\
\hline Mode Pengkodean & inter \\
\hline
\end{tabular}

\subsection{Transmisi Video Tanpa Kanal Error}

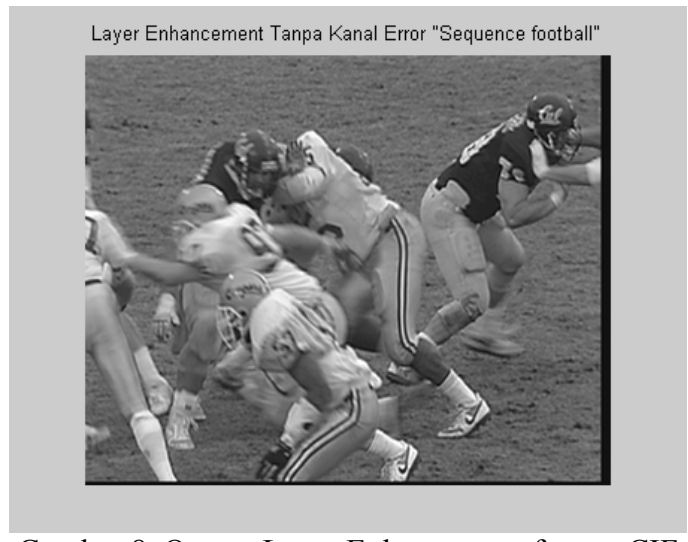

Gambar 8. Output Layer Enhancement format CIF Tanpa Kanal Error 


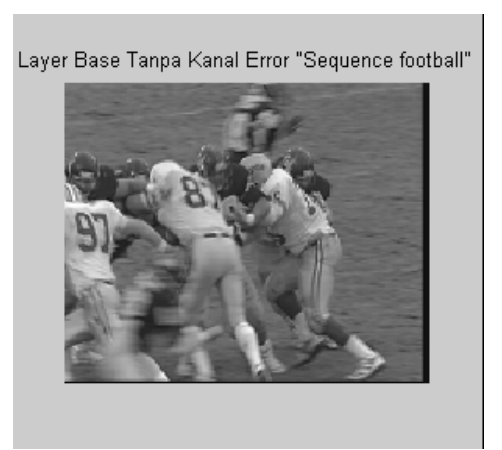

Gambar 9. Output Layer Base format QCIF Tanpa Kanal Error

Hasil simulasi pada sequence "Football" didapatkan bentuk grafik dengan nilai PSNR untuk layer base rata-ratanya $29.683 \mathrm{~dB}$ dan layer enhancement rata-ratanya $78.917 \mathrm{~dB}$, bentuk grafik dengan nilai MSE untuk layer base rata-ratanya $69.998 \mathrm{~dB}$ dan layer enhancement rata-ratanya $0.000834417 \mathrm{~dB}$.

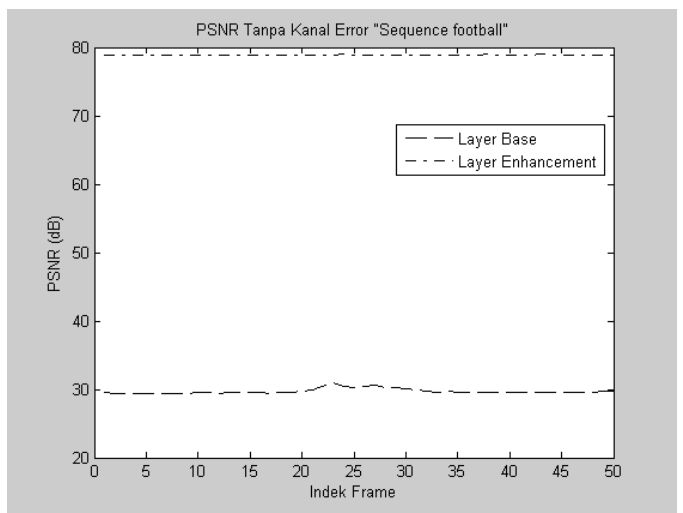

Gambar 10. Grafik PSNR Tanpa Kanal Error

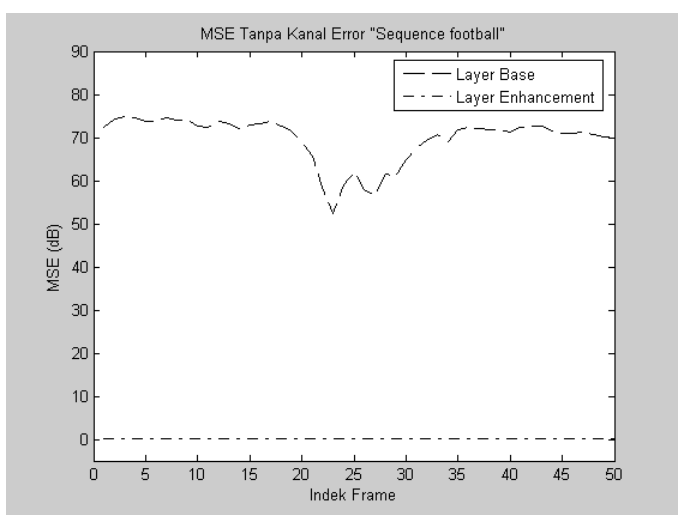

Gambar 11. Grafik MSE Tanpa Kanal Error

\subsection{Estimasi Gerak dan Kompensasi}

Hasil simulasi estimasi gerak pada video coding dengan menggunakan metode Gradient Descent (penurunan gradien) dapat diperlihatkan pada gambar 12 didapatkan rekonstruksi target frame, anchor frame dan vector gerak serta prediksi frame.

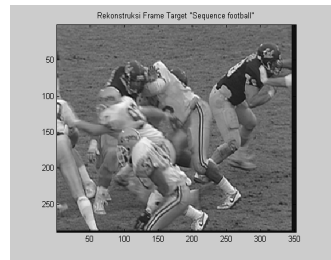

(a)

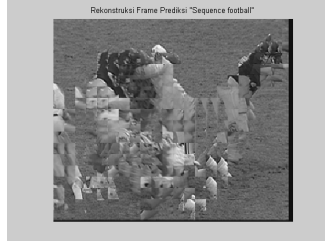

(c)

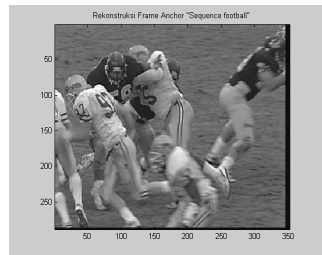

(b)

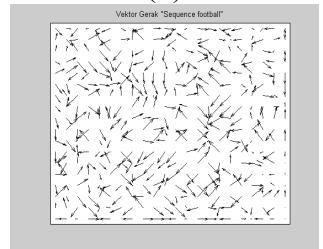

(d)
Gambar 12. Rekonstruksi Motion Estimation PSNR $=18.96 \mathrm{~dB}$, (a) Target Frame, (b) Anchor Frame, (c) Prediksi Frame dan (d) Vektor Gerak

\subsection{Transmisi Video Dengan Kanal Error}

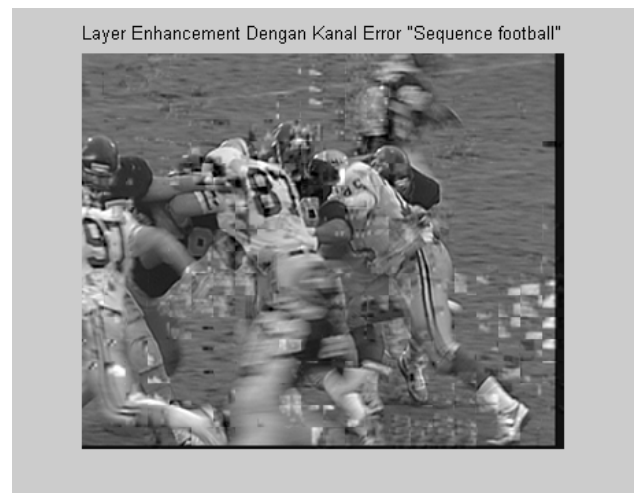

Gambar 13. Keluaran Layer Enhancement Format CIF Dengan Kanal Error

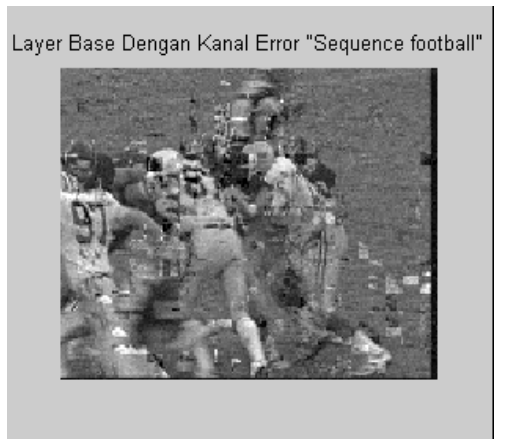

Gambar 14. Keluaran Layer Base Format QCIF Dengan Kanal Error

Paremeter pemberian Error (Lost vector) dengan noise Gaussian pada bidang spasial frame sequence football dimulai pada frame ke-10 dengan kecepatan frame (frame rate) 30 frame/second. Hasil simulasi pada sequence "Football" didapatkan bentuk grafik dengan nilai PSNR untuk 
layer base rata-ratanya $23.018 \mathrm{~dB}$ dan layer enhancement rata-ratanya $43.142 \mathrm{~dB}$, bentuk grafik dengan nilai MSE untuk layer base rata-ratanya $381.069 \mathrm{~dB}$ dan layer enhancement rata-ratanya $131.241 \mathrm{~dB}$.

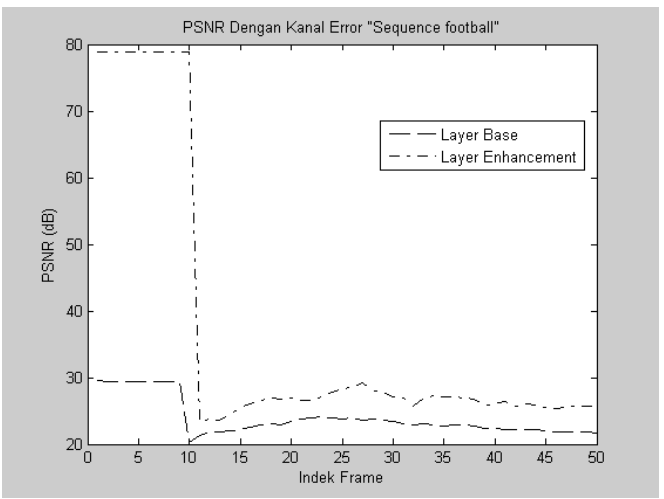

Gambar 15. Grafik PSNR Kanal Error

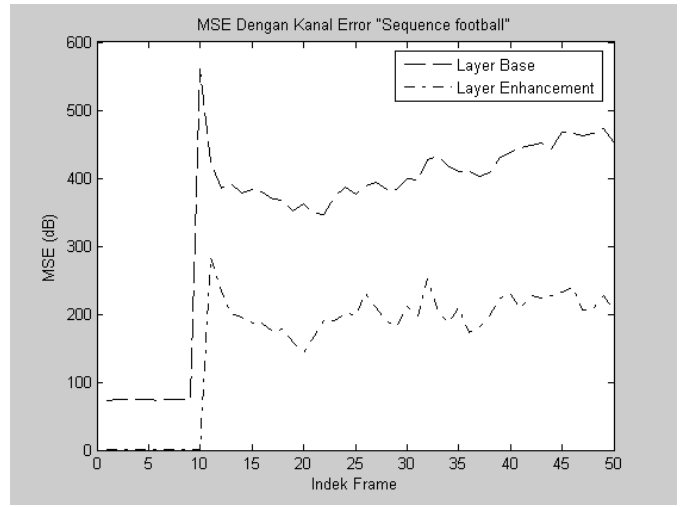

Gambar 16. Grafik MSE Kanal Error

\section{Kesimpulan}

Dari hasil simulasi yang telah dilakukan dapat disimpulkan :

a. Pada transmisi tanpa kanal error didapat PSNR layer base sebesar $29.683 \mathrm{~dB}$ dan layer enhancemenet $78.917 \mathrm{~dB}$ dan untuk MSE layer base sebesar $69.998 \mathrm{~dB}$ dan layer enhancemenet $0.000834417 \mathrm{~dB}$

b. Pada transmisi kanal error mempengaruhi kualitas dari video sequence yang ditunjukkan dari penurunan nilai PSNR layer base sebesar $23.018 \mathrm{~dB}$ dan layer enhancemenet $43.142 \mathrm{~dB}$ dan untuk MSE layer base sebesar $381.069 \mathrm{~dB}$ dan layer enhancemenet $131.241 \mathrm{~dB}$.

\section{Daftar Pustaka:}

D. Wu, Y. T. Hou, and Y.-Q. Zhang, Dec. 2000, "Transporting real-time video over the Internet: challenges and approaches," Proc. IEEE, vol. 88, pp. 1855-1877.
Dapeng Wu, Yiwei Thomas Hou, Wenwu Zhu, YaQin Zhang, Jon M. Peha, March 2001, "Streaming Video Over the Internet: Approaches and Directions", IEEE Trans. On Circuit and System for Video Technology, vol.11, No.3.

Fan Zhai, Randall Berry, Thrasyvoulos N, Pappas, Anggelos K. Katsaggelos, 2003, "A RateDistortion Optimized Error Control Sheme For Scalable Video Streaming Over The Internet", ICME.

Mohammed Ghanbari, 1999, "Video Coding an Introduction to Standart Codecs", The Institut of Electrical Engineers, United Kingdom.

W. Li, March 2001, "Overview of fine granularity scalability in MPEG-4 video standard," IEEE Trans. Circuits Syst. Video Technol., vol. 11, pp. 301-317.

Yao Wang, Jorn Osterman, Ya-Qin Zhang, 2002, "Video Processing And Communications", Prentice Hall, Inc, New jersey. 
Volume 4, Edisi 1, November 2017

$\mathbf{3 0} \mid \mathrm{H}$ a 1 a $\mathrm{m}$ a $\mathrm{n}$ 